\title{
AS VARIAÇÕES "PAISAGEIRAS"1 NA CIDADE E OS JOGOS DA MEMÓRIA
}

\author{
Cornelia Eckert ${ }^{2}$
}

\begin{abstract}
Para que nasça a paisagem é preciso inegavelmente que a pulsação da vida, na percepção e no sentimento, seja arrancada à homogeneidade da natureza e que o produto especial assim criado, depois de transferido para uma camada inteiramente nova, se abra ainda, por assim dizer, à vida universal e acolha o ilimitado nos seus limites sem falhas. (Simmel apud Maldonado 1996: 17)
\end{abstract}

\section{Deslocamento e reconciliação}

Pierre Sansot, um filósofo francês, intitulou de Variations Paysagères o estudo que faz sobre as experiências humanas com a paisagem enquanto um sistema de troca entre o mundo sensível e o mundo das significações (Sansot, 1983: 24). Seja no enraizamento a um lugar de pertencimento seja no deslocamento pela diversidade de lugares vividos, importa-nos como a experiência humana ofereceu-se aos sentidos, ao olhar, à escuta, ao cheiro, ao gosto. Nesses jogos perceptivos, são colocadas em destaque as formas sensíveis que movem os habitantes em suas lógicas de viver os espaços e tempos culturais. A paisagem é em Sansot essa experiência humana plural e descontínua onde os sujeitos em suas biografias relacionam imagens motivados pelo saber e pelo imaginário. A paisagem estará lá onde a vida pulsa na qualidade de estar no mundo social, na percepção daquele que a consente na imaginação. O que está em jogo é um reencontro após o deslocamento entre aquele que sente e o sensível, sem hesitar aqui fazer também referência à estética, sempre presente como um fato de cultura. Este princípio de visibilidade prolonga-se na palavra, que na sua ressonância narrativa dilata a percepção agora em uma paisagem narrada a qual faz vibrar as formas sensíveis.

Tal deslocamento já estava presente na obra de Georg Simmel sobre o tema da paisagem. Esta nasce na nossa atividade criadora essencialmente humana, de se deixar evocar por um estado psíquico (stimmung) que articula percepção e afeição, que se separam e se reaproximam, se associam e se dissociam "como dois aspectos do mesmo ato" (Maldonado citando Simmel, 1996: 6 a 8). Como esclarece Simone Maldonado, "é esse sentimento da ordem da subjetividade e da

\footnotetext{
${ }^{1}$ Vou me permitir a esta tradução da palavra francesa de 1846 relacionada à paisagem, ou segundo Petit Roberts, caracterizada pelo interesse de paisagens. Neste texto, um neologismo para dar ao tema da paisagem, uma dinâmica importante aos estudos das formas de sociabilidades e da memória coletiva.

${ }^{2}$ Agradeço ao Prof. Flávio Leonel Abreu da Silveira (UFPA) pelo convite para participar do II Fórum Temático Paisagem e Cultura: Dinâmicas do Patrimônio e da Memória na Atualidade na Universidade Federal do Pará, Belém, 5 a 7 de dezembro de 2007 na Mesa Redonda: Paisagens, Patrimônios e Dinâmicas da Memória. Minha participação foi financiada pelo Projeto Procad Amazonas e agradeço aos coordenadores Maria Eunice Maciel (UFRGS) e Heraldo Maués (UFPA) pelo apoio.
} 
afetividade que vai permitir que um determinado pedaço de natureza venha a se constituir em uma paisagem" (Maldonado, 1996: 8).

No entanto, a paisagem como construto social no mundo moderno pode ser estruturada e organizada para além da sensibilidade de origem e transformada em sistema de signos. O indivíduo nessa intenção quer sua permanência na matéria construída a qual requer formas duráveis, quando não políticas de intervenção para a salvaguarda do ato humano. Todavia, mesmo mediante o espaço construído, o homem acolherá as modificações que se impõem ao seu olhar. Isto é suficiente para que ocorra "paisagem" (Sansot, 1983: 35), experiência possível pela evocação das imagens que nos habitam na memória coletiva.

A construção da paisagem na trajetória humana não se reduz a deixar reger-se por modelos culturais ou por a prioris externos à consciência humana, mas de intenções afetivas, de motivações singulares que acomodam as sensibilidades potencializadas por um universo de signos e de imagens dando ritmo aos deslocamentos em nossos percursos, em nossa trajetória, circulando sentidos no nosso tempo pensado e vivido.

Nesse processo exclusivamente humano, embarcamos na aventura de refletir sobre as paisagens urbanas. Trata-se da peripécia de associar a motivação individual com a duração no social, apreendendo a paisagem no seu estado alternativo de ser fragmento de uma totalidade. Detemo-nos nas formas de reciprocidade da vida em contextos urbanos tal qual nos estimula a obra de Sansot, a qual nos orienta sobre a noção das variâncias das experiências subjetivas de paisagens da vida urbana que deslizam o ser para reciprocidades cognitivas entre um mundo subjetivo e um mundo objetivo. E como nos lembra Simmel, nesse processo os indivíduos interagem dando ritmo à vida social. Os habitantes investem nas formas de continuar na vida social do interagir cotidiano em suas memórias e trajetórias, perscrutando paisagens, arranjando as imagens em constelações em que podem acomodar as sensibilidades e desejar a continuidade da experiência de jogar o social.

Nessa perspectiva, problematizamos o tema da paisagem onde há disposição do ser em sua reflexividade. A paisagem nasce da experiência temporal articulada ao movimento da sensibilidade, como um projeto de experiência narrativa que concilia na memória compartilhada a existência do grupo compreendido na disjunção do todo da natureza.

\section{Notícia etnográfica}

De 1987 a 1991, quando desenvolvi um estudo na França sobre a vida de uma comunidade de mineiros de carvão, chamava atenção a forma como ao longo do século XX desenvolveu-se um sentimento de pertencimento local e regional vinculado ao território cultural de Cévenne, amalgamando a diversidade étnica de uma mão-de-obra recente vinda de diferentes países 
da Europa e da África. A construção social das identidades narrativas relacionava-se, nesse estudo, ao sentimento de enraizamento ao lugar. Os velhos mineiros franceses, espanhóis, poloneses, africanos de La Grand Combe, quando narravam sobre suas sagas imigratórias e migratórias tão diversas, definiam suas permanências nessa cidade no sudoeste da França após o fechamento das minas nos anos 1970 e 80, por razões práticas e simbólicas plurais. Contudo, o tom emocional era em torno da interação a uma comunidade ocupacional colocando como dramática de pertença o “viver e morrer" no país cevennol, "lutar ou morrer" pela paisagem cevennol. Em suas narrativas, promoviam a força de sentido da memória coletiva na orientação de um projeto de enraizamento ao lugar que lhes inscrevera no valor trabalho (de mineração) e na comunidade de destino. Os slogans eram repetidos em dialeto Langue d'Oc, o mesmo que usavam para as lutas de resistência ao fechamento das minas desde os anos 60. Fenômeno estudado por Pierre Bourdieu e por Alain Tourraine, em torno do amor pela paisagem construía-se um símbolo de unidade dos mineiros trabalhadores de subsolo não importando "no discurso sobre a luta" suas origens diversas.

A paisagem era sistema de signos em que podiam acomodar uma luta de identidade regional e recriar a saga de mais de um século de proletarização, mesmo que desterritorializados de seus territórios afetivos de origem. A paisagem, nesse processo de construção de uma identidade da categoria regional, amalgamava pertenças locais diversas em face a um estado de poder centralizador e reformista das lógicas econômicas do Estado-Nação francês.

Os mineiros inovavam em suas narrativas a relação a um mito fundador de pertencimento regional, a celebração da paisagem e ao espírito de identidade pela resistência à morte da mina. As torres de extração desativadas nas planícies cevenóis proliferavam-se como signos de identidade de um luto comum. Em face da demolição de usinas e casas vetustas, lutavam pela permanência no território-paisagem. A paisagem era ressemantizada como território de unidade de sentido de suas trajetórias heróicas, configuradora de suas identidades individuais e sociais.

Abordei as imagens evocadas em suas memórias através da estratégia da etnografia da duração ${ }^{3}$, na observação, na escuta, na pesquisa de seus acervos, nas imagens produzidas. Trabalhar então com a cidade industrial em sua demolição, em sua crise pela transformação por novos tempos, orientava-nos para a importância de aderirmos à noção de paisagem simbólica do movimento da vida no que tange ao campo antropológico de tratar do tema do viver na cidade a partir do tempo narrado pelos seus habitantes apreendidos na etnografia.

\footnotetext{
${ }^{3}$ Etnografia da duração foi termo cunhado pelas autoras e divulgado em ECKERT, Cornelia e ROCHA, Ana Luiza Carvalho da. "Imagens do tempo nos meandros da memória: por uma etnografia da duração". In: Koury, Mauro G P. (org.). Imagem e Memória: Estudos em Antropologia Visual. Rio de Janeiro: Garamond, 2000, no artigo "Imagens do tempo nos meandros da memória: por uma etnografia da duração".
} 
De retorno ao Brasil, junto com a colega Ana Luiza Carvalho da Rocha, elaboramos um projeto integrado para tratar do tema da cidade em suas múltiplas interfaces coletivas circunscritas na paisagem urbana. Em 1997, criamos então uma prática de estudo que consiste em desenvolver pesquisas etnográficas na cidade bem como garimpar acervos de imagens como uma alquimia para nós significativa para apurar o mundo sensível das formas plurais de interagir, agir, construir, dialogar e representar os diferentes níveis da vida social urbana. Nosso lugar de pesquisa é a cidade de Porto Alegre, sendo o local onde, desde então, dedicamos nosso estudo.

Nosso esforço de pesquisa na cidade de Porto Alegre é focado no estudo dos itinerários urbanos e das formas de sociabilidade, das intrigas e dos dramas que configuram o teatro da vida citadina. Tendo por base uma multiplicidade de etnografias nas ruas, nos bairros, na vida coletiva nos dias de hoje, refletimos sobre a complexidade antropológica das estruturas espaço-temporais, sob as quais se assentam os fenômenos da alteridade e da experiência humana no mundo contemporâneo. Tais pesquisas no âmbito do projeto denominado Banco de Imagens e Efeitos Visuais têm por mote o estudo das formas do tempo sobrepostos e configurados nos jogos da memória dos habitantes. A pesquisa etnográfica de cada pesquisador é concebida pela produção imagética (fotografia, vídeo, som, escrita, estudo de acervo) e dispostos à interação dos usuários e pesquisadores do banco de dados fixo e do banco em web disposto em forma de museu virtual para acesso dos usuários (Eckert e Rocha, 2007).

Daí nossa motivação de tratar as variações paisageiras na arte do viver na cidade, do agir e do narrar captado em vídeos etnográficos, em narrativas fotográficas, em etnografias sonoras e etnografias escritas. Para esta proposta, é o tema da memória coletiva que aderimos para evocar as práticas sociais e os sentidos de jogar o social.

Ao tratarmos do tempo vivido narrado, é da estetização da vida cotidiana na pluralidade de formas sociais que concebem as práticas e saberes dos seus habitantes, que seguimos o movimento constante de evocação das imagens de suas experiências de viver as paisagens urbanas no fluxo do tempo. Em relação à noção de uma paisagem urbana constantemente criada e recriada na adesão aos lugares de interação social, buscamos as referências às formas sensíveis que concebem a trama da paisagem construída nos ritmos dos habitantes refletirem sobre os sentidos de ser na cidade.

A pesquisa sobre o tempo vivido na cidade almeja apreender essas paisagens urbanas na memória coletiva dos citadinos nos espaços cotidianos. Cada narrativa escutada, cada imagem captada, cada diário de campo lido e monografia construída são para nós o ato de "transcriar" (como diria o poeta Haroldo de Campos, 2007) as paisagens compartilhadas pelo etnógrafo da 
cidade como "pontos de amarração" (Bosi, 2003: 70) de trajetórias singulares, de histórias comuns, “de processos afetivos exclusivamente humanos" (Simmel apud Maldonado 1996: 8).

\section{Ressonâncias e dissonâncias da paisagem urbana moderna}

As formas e a cultura urbana que configuram as paisagens na modernidade são questões igualmente tematizadas na obra de Georg Simmel. O estar em sociedade é também disjunção pelo conflito. Um movimento intrínseco à variedade das formas da vida social em seus paradoxos e contradições que estetizam as múltiplas dimensões da existência humana no presente.

É na sociedade complexa que Simmel acomoda um conceito possível de paisagem relacionada aos atributos de consciência da socialização como processo. A paisagem urbana será uma pluralidade de relações, um em relação ao outro, ao nós, ao eles, ao tu. Trata-se da variedade de formas socializadoras onde os indivíduos atualizam os sentidos coletivos que criam e recriam a vida. Nessas formas de reciprocidade, ressoam os dispositivos de sentimentos sociais em que podemos vislumbrar as estéticas das interseções em que cada indivíduo, em sua liberdade, é confrontado a interagir. Jogar o social é assim para cada citadino o tempo de escolhas, de motivação de possibilidades de se colocar à disposição do movimento de viver na paisagem urbana que acaba por amalgamá-los em um evento psíquico em que podem dispor das orientações recíprocas para interpretar as formas de ligação, de dissociação, de ação e disjunção, de negociação e de conflito.

Como mostra Moraes Filho em seu estudo sobre Simmel, sua obra quis tonalizar o permanente vir-a-ser da vida social onde "não há propriamente sociedade feita, mas antes o fazer-se sociedade" (Moraes Filho 1983: 31) que tal como a paisagem, é obra do caráter temporal da experiência humana. Nessa perspectiva, o ato de criar e recriar é a pulsão da interação, da relação recíproca nos quais se encontram instintos e fins.

As formas de viver socialmente são variadas e implicam em dissonâncias de dominação e subordinação de uma em relação à outra, e no interior de cada uma delas. Simmel está, pois, atento ao conflito eternamente gerado nas formas sociais como ingrediente da interdependência das ações sociais. Para tratar o ser humano, é sobre o senso das diferenças que devemos nos debruçar, sendo necessário sempre um sentimento de deslocamento e diferenciação ao lado da unidade para torná-la perceptível e eficaz (Moraes Filho 1983). Como uma arte combinatória das variações paisageiras, relaciona-se formas sociais como dinâmicas de dramatizar identidades e diversidades, onde as paisagens da vida urbana são configuradas nas interseções de processos motivados na vida objetiva e na vida subjetiva.

Nesse paradigma hologramático, a cultura objetiva é produto da estrutura na tensão com a cultura individual em que os indivíduos, a partir de motivações e interesses diversos, atuam 
nas interações sociais. Nesse jogo de formas possíveis, a multiplicidade de laços depende das configurações que enlaçam os indivíduos nessas reciprocidades. No entanto, diz Simmel, "a cultura individual modela e é modelada pela cultura objetiva. E o problema que se coloca é que a cultura objetiva chega a ter vida própria" (Simmel apud Waizbort 2000: 116). Como orienta Leopoldo Waizbort, para Simmel estas são estruturas cristalizadas de interações que se autonomizam no enfrentamento ao individuo como se fossem poderes alheios (Waizbort 2000). É esta a tragédia da cultura preconizada na obra de Simmel nos processos de socialização na vida urbana-moderna oriunda da tensão entre opostos que acabam se consolidando como determinismos sociais no âmbito da própria sociedade.

\section{Paisagem com patrimônio tombado: tragédia da cultura?}

Simmel vai relacionando a noção de paisagem à intensidade de pulsionar os sentidos no lugar, vividos nas formas de interação dos indivíduos em suas reflexividades e reciprocidades com o mundo que lhes abriga e onde podem interagir com outros e onde investem na continuidade de formas de sociação e de círculos de agregação.

A variância paisageira é, assim, o trabalho da memória coletiva numa lógica social de significações (Eckert e Rocha, 2007). Tal experiência, no sentido ideal de Simmel, ocorre no processo interativo da cultura individual e da cultural social, onde a cultura subjetiva modela e, ao mesmo tempo, é modelada pela cultura objetiva. Nessa perspectiva simmeliana, um problema se coloca: a cultura objetiva, como já anunciei anteriormente, chega a ter vida própria como a circulação do dinheiro que modifica as relações dos indivíduos lhes determinando uma racionalização de divisão de trabalho pela lógica de um sistema financeiro que se movimenta em uma esfera abstrata.

Também a paisagem que é apropriada como objeto de política cultural pode ser analisada sob a noção de tragédia da cultura de Simmel. Trata-se de problematizar os critérios que determinam a classificação de paisagens e lugares objetivados como patrimônio a ser conservado. Enquanto monumento, sua forma é congelada pelo propósito de lei. A paisagem antes vivida no tempo e espaço da experiência humana é mote de representação institucional sob argumentos de uma memória histórica que deve ser patrimonializada. Essa história monumental afasta o movimento de relações recíprocas dos indivíduos e da vida coletiva. Opera-se uma "distância entre o produtor e o produto, que conduz até o ponto em que o produtor não se reconhece mais na sua ação e, nesse sentido, assistimos a uma dissociação entre a personalidade criadora e a obra criada, e tudo se passa como se a obra adquirisse uma existência autônoma pela relação aos produtores" (Watier 2003: 125). 
Poderíamos assim selecionar inúmeros exemplos de paisagem intocada pelo tombamento constitucional. A questão é complexa e podemos sugerir uma performance: um indivíduo moderno viveu em um dado tempo e espaço a experiência da emoção de poder depositar em uma fonte d'água esquecida em um bairro imêmore suas reminiscências afetivas. Acontecimentos de sua infância o fazem evocar as imagens de suas lembranças e laços. Mediante a exclusão do lugar, passa a reivindicar, na instância da estrutura política, a salvaguarda e a permanência do território mito. Para tanto, demanda a intervenção política do congelamento da forma que passa a ser legislada por uma lógica objetiva como a do turismo, da revitalização, da área protegida. Paradoxalmente, nessa lógica, este indivíduo é doravante impedido de interagir nesse lugar, transformado em espetáculo e objeto de culto. O lugar, além de esvaziado de interações e interlocuções, é interditado às formas de reciprocidade cotidiana. As atuações são controladas por estruturas de poder legitimados por discursividades que representam uma paisagem como tributária de um tempo ideal no passado social.

A demanda individual operou, neste nosso exemplo, pela ânsia de institucionalizar a experiência afetiva, resultando na reivindicação da intervenção política com poder de eternizar a paisagem patrimonializada e interditada ao gesto criador. Como diziam os "meus" mineiros entrevistados, este indivíduo poderá repetir o sentimento que lhes povoava na época da minha pesquisa: "a modernidade nos traiu".

É possível encontrar outro exemplo no trabalho de Simmel sobre a ruína, a que Ana Luiza e eu costumamos recorrer em nossas orientações no Biev. Para ele, a ruína é fundadora de imaginários e motivações emocionais. Esta mesma ruína pode ser signo de degradação para o discurso urbanístico que demanda intervenção do Estado. Simmel pergunta nesse âmbito por que tememos a ruína que nos inspira as lembranças? Por que essa paisagem não pode durar na sua condição de luto? A ação política mais provável será de restauro para um simulacro de continuidade. Sobre a ruína, a macro esfera impõe a reforma e ressemantiza seus sentidos pela higienização e/ou pela espetacularização. A especulação imobiliária ganha terreno ou a lógica do mercado patrimonial para operar essa cimentação da paisagem como patrimônio cultural censurando ao convívio descontínuo. Para ser tombada no livro das artes ou no livro das paisagens, sofre a inferência da política de restauro à revelia das artes de viver o lugar.

Para Henri-Pierre Jeudy, tal política de museologização define-se a partir de uma ordem simbólica cimentada no passado, é "uma necessidade de cultura traduzida por uma objetalização das culturas" (Jeudy 1990: 2). Um ato jurídico determinado pela ordem política que desqualifica a vida civil de aprender a ruína como devir, ou como pondera Jeudy, "em qualquer trabalho de restituição ou de reconstituição, uma execução ótima, sem falha, sem indeterminação, 
só faz reconduzir à ausência aterradora de um jogo entre a morte e a memória”. (Jeudy 1990: 3). Aderimos a sua crítica às políticas patrimoniais as quais desconsideram que o fenômeno urbano é o resultado da ação recíproca de indivíduos e de grupos no plano de trocas sociais, como elucida Simmel.

Para nós, e falo aqui a partir do projeto integrado Banco de Imagens e Efeitos Visuais, portanto a partir do campo da antropologia urbana e da imagem, argumentamos para a importância dos gestores do patrimônio escutarem uma comunidade semântica que trata das formas específicas dos arranjos da vida social na cidade segundo a complexidade dos gestos acumulados de seus habitantes, seja para a compreensão do processo de territorialização/desterritorialização de identidades sociais no mundo contemporâneo; seja para o entendimento da descontinuidade/continuidade sistêmica de valores acionados por esses habitantes. Ou, ainda, para a compreensão de redes/espaços sociais onde se situam tais habitantes conforme suas trajetórias, posições e papéis, suas adesões e suas dissidências a certos lugares do contexto citadino. Essa crítica ao processo de objetificação no mundo contemporâneo confunde-se com a intensa desconfiança epistemológica ou ética da Antropologia em relação aos discursos universais ou totalizantes.

A questão patrimonial, hoje, constrói uma condição privilegiada para o fazer antropológico tratar das variações paisageiras na cidade. E aqui, sobretudo, introduzimos a estratégia de produzir conhecimento sobre a condição urbana e o papel do estudo da memória coletiva dos habitantes na cidade no contexto atual, onde política e ciência dialogam para promover as "identidades narrativas" (Ricoeur 2000), as quais detêm a capacidade de subverter a idealização da linearização do tempo.

\section{Paisagem e memória: etnografia da duração}

Como o leque de referências teóricas terá que ser aqui pontual, podemos nos concentrar nas provocações intelectuais de autores tão díspares como Georg Simmel e Gaston Bachelard (embora o segundo não raro diz seguir o primeiro), porém aproximando-os no que se refere à perspectiva de tratar da noção da paisagem à luz da dialética do espaço captada nos deslocamentos dos habitantes na cidade como nos ensina Walter Benjamin e, por outro lado, em autores da linhagem de hermenêutas da tragédia como Gilbert Durand, Paul Ricoeur, Michel Maffesoli, Pierre Sansot entre outros, em suas competências de instaurar a noção da memória como espaço fantástico permitindo conceber nas experiências dos espaços vividos, o tempo em suas imagens e em seus imaginários, “epifania de mistérios” (Durand 1998). 
A condição principal de requisitos para a confiança dos habitantes nas formas de viver de sua cidade, sendo essa um território de pertença, seja ela qual for, não reside apenas no abuso dos poderes públicos em disponibilizar a esses habitantes seus equipamentos urbanos. A confiança dos habitantes em sua cidade depende da "circularidade dos sentidos" (Bakhtin 1993) produzidos nas diferentes ações destrutivas e criativas (Nietzsche apud Harvey 1992), que transformam ou preservam os espaços que eles almejam, de lugares de referência identitária onde possam produzir formas interativas de viver uma trajetória coletiva e de narrativas intra e intergeracionais, nas quais reside a importância da transmissão de valores simbólicos.

Espaços de debate como este fórum nos permitem suspeitar das políticas de patrimonialização que se fecham ao movimento da experiência humana articuladas nas ações recíprocas. A pesquisa antropológica nas cidades brasileiras tem buscado apontar para as reflexões dos habitantes sobre os sentidos dos lugares urbanos depositórios das memórias singulares na vida pública pela qualidade de suas formas de interação.

Em seu estudo, Alain Corbin refere-se à paisagem como a maneira de o homem ler e analisar o espaço, de representação e apreciação estética (Corbin 2001:11). Uma leitura que para Gilbert Durant é imaginação criadora (1989) do impulso oriundo do ser. Na prática de rememoração, a paisagem é empreendida como experiência de evocação simbólica. Assim, o trabalho de tecer as reminiscências é configurar as variações paisageiras consteladas por imagens da experiência de viver nos lugares no fluxo do tempo. Gaston Bachelard em sua fenomenologia do imaginário (Durand 1988: 67) estabelece a plenitude das imagens: "o imaginário confunde-se então com o dinamismo criador, a amplificação poética de cada imagem concreta" (Durand 1988: 68). Bachelard postula uma meditação fantástica para o tempo vivido como ritmos temporais em que podemos localizar a vida social. Durar na paisagem significa essa qualidade de "formar imagens que ultrapassam a realidade, que cantam a realidade" (Bachelard apud Pessanha 1988: 153). Na imaginação criadora distinta da imaginação reprodutora, Bachelard confia os ritmos encontrados do tempo pensado que ressoa em nós. Esse caráter temporal da experiência humana torna a paisagem urbana o lugar dos sentidos que articula narrativas e performances dos atores em suas dramáticas na cidade. Esse é o setor da palavra humana, ou seja, "da linguagem que nasce, jorrando do gênio da espécie, ao mesmo tempo língua e pensamento: uma linguagem poética" (Durand 1988: 65).

Na pesquisa que desenvolvemos no Banco de Imagens e Efeitos Visuais, que tem por mote o estudo antropológico na cidade de Porto Alegre fazendo recurso das novas tecnologias e que vamos apresentar para vocês na mesa redonda amanhã, tomamos a cidade como objeto temporal, sob a perspectiva de uma figuração de seus cenários em que atuam os grupos/indivíduos (Eckert e Rocha 2007). Nas etnografias que Ana Luiza e eu temos orientado no âmbito do projeto sobre 
jogadores de futebol nas várzeas das periferias da cidade, sobre os habitués da Rua da Praia, calçadão no centro da cidade, sobre a relação de rede familiares nos processos de demolição de casas herdadas ou construídas, sobre as performances e jogos de interação nas feiras livres, sobre a relação dos habitantes do bairro insular com as águas em suas práticas como a de pesca, etc, a paisagem do mundo urbano contemporâneo guarda as feições das estratégias de vida de seus habitantes, seus sonhos e desejos, conforme a acumulação benéfica da animação e da vibração temporal dos ritmos diferenciais de ocupação e apropriação de seus territórios. A cidade de Porto Alegre (e outras cidades que temos estudado no interior do Rio Grande do Sul e em outros Estados) mostra-se a partir dos gestos, olhares e performances de seus moradores; dos itinerários, dramas e intrigas vividos por eles; das formas de sociabilidades na vida cotidiana, nos bairros, nas ruas, nas casas, nos clubes, etc, espaços repletos de trajetórias e itinerários, memórias e imagens a ele atribuídos.

O cotidiano torna-se assim uma dimensão construída nos jogos interativos e ordenados pelos habitantes em suas memórias ritmadas em temporalidades descontínuas que elucida sobre o "como" e o "porquê" dos laços coletivos, bem como os contextos sociais onde são vividos e negociados. Nesta, evocamos o tema das variações paisageiras na forma como os citadinos conciliam suas narrativas e gestos com a pertença ao lugar, acomodando na matéria as lógicas imaginárias. Essa ritmicidade dimensiona a experiência temporal em seus detalhes, fragmentos, instantes vividos, subvertendo as estruturações institucionais que imprimem uma representação sobre a realidade social: a economia, a política, a educação, as tecnologias, etc.

Cabe aqui acentuar que para nós, esta antropologia dos ritmos temporais é perscrutada no estudo da vida cotidiana no contexto urbano, cenário em que as narrativas dos habitantes referem-se às paisagens que abrigam suas referências em percursos e itinerários em que atribuem identidades sempre em perspectiva de um vir-a-ser. Paul Ricoeur é, para nós neste ínterim, uma referência importante em "Tempo e Narrativa" e o "Si mesmo como um Outro" por nos provocar a tratar da experiência vivida no tempo da ação narrativa. Ricoeur concebe os personagens da experiência em sua inteligência narrativa. Nesse sentido, as etnografias que desenvolvemos sobre as paisagens urbanas pensadas e vividas no trabalho da memória dos habitantes buscariam o sentido dessa relação na experiência narrada. Pela ação narrativa, Paul Ricoeur compreende a construção de uma identidade de um si mesmo relacional, deslocando a percepção de uma paisagem externa a sua experiência (uma mesmidade) para a reflexão sobre lugar vivido pelo narrador na identidade ipseidade.

A etnografia da duração, nessa perspectiva, vislumbra o tratamento da memória narrada como conhecimento de si e do mundo, a partir do trabalho de recordar narrado pelos 
sujeitos, "o que equivale a dizer que não nos recordamos por simples repetição e que devemos compor nosso passado... a humanidade é a narração, não a recitação" (Bachelard 1988: 51). O narrador reconstrói os sentidos do presente e dos lugares em que podem, no presente, depositar suas memórias. O presente é sempre movimento e transformação, que instaura a rememoração do passado sempre restaurado (Benjamin 1993: 16). Posto que a rememoração do passado não implica simplesmente a sua restauração, mas também uma transformação do presente tal que, se o passado perdido aí for reencontrado, ele não fique o mesmo, mas seja, ele também, retomado e transformado. (Benjamin 1993: 16).

Também o próprio antropólogo é concebido como narrador de sua cidade, seus jogos da memória compartilhados com os leitores e usuários das experiências de interação no viver urbano, disponibilizadas no nosso portal www.estacaoportoalegre.ufrgs.br. As experiências em suas trajetórias são interpretadas e comunicadas na forma narrativa. As paisagens são estetizadas na memória narrada e por nós interpretadas e editadas em diversos suportes como o texto escrito, videográfico, fotográfico e sonoro. Os jogos da memória no banco de imagens são então disponibilizados para interpretação dos interlocutores que interagem na condição pública (internet) com a memória compartilhada.

Em decorrência, os espaços urbanos construídos e vividos, como objeto do estudo etnográfico, vão se revelando não meros reflexos de políticas urbanísticas, mas suportes de tradições e biografias de seus habitantes cujas narrativas expressam uma linguagem coletiva que comunica uma pluralidade de identidades e memórias (Eckert e Rocha, 2007).

Fica aqui ainda a questão que Paul Ricoeur aponta acerca da interpretação narrativa, no sentido de ver até que ponto ela é deslocamento epistemológico sobreposto à história relatada e à história que se edifica sobre os rastros da pesquisa documental (Ricoeur 2000: 300). Todavia, não são certamente os traços de intersubjetividade da percepção que são destacados no estudo narrativo em que há mediação simbólica entre as motivações da ação humana e a experiência narrada. Há, na experiência da memória compartilhada na narrativa, a função de re-ligar a comunidade da narrativa aos lugares itinerantes da memória (Ricoeur 2000: 186 e 311). Nesse sentido, os espaços públicos e/ ou outros do domínio privado fornecem o suporte material de um investimento simbólico referido ao cotidiano afetivamente significativo de seus grupos sociais. Não se pode esquecer aqui que toda obra humana remete a uma produção simbólica, sendo os territórios de sociabilidade de uma cidade, nichos de sentidos produzidos por uma comunidade, não para concluir apenas sobre os sistemas de dominação subjacentes, mas para interpretar sobre os significados que configuram as diferentes formas e planos de existência social em seu interior. (Eckert e Rocha 2007). 
Portanto, tratar das variações paisageiras na cidade, nos remete a estas formas e planos, de lugares vividos como guardiões da memória de seus habitantes. Como os habitantes de La Grand-Combe e em especial a última geração de mineiros de carvão franceses com que convivi nesta cidade, a paisagem é o espaço fantástico em que podem "colar" sua existência aos ritmos temporais de interação social vividos nos lugares e territórios em que investem a duração de suas biografias. Hoje, esta é a nossa pesquisa em Porto Alegre ou outra cidade moderna: conceber a paisagem que dura na memória compartilhada nos reencontros, nas sociabilidades, na vida cotidiana, narrada pelos seus habitantes.

\section{Referências}

BACHELARD, Gaston. A dialética da duração. São Paulo: Ática, 1988.

BENJAMIN, Walter. "O narrador. Considerações sobre a obra de Nikolai Leskov" In: Magia e técnica, arte e politica. Ensaios sobre Literatura e Historia da Cultura. São Paulo: Brasiliense, (197-221) 1993.

BENJAMIN, Walter. "O flâneur". In: BENJAMIN, Walter. "Sobre alguns temas em Baudelaire". In: Charles Baudelaire um lírico no auge do capitalismo. Obras escolhidas volume III. São Paulo: Ed. Brasiliense. (185-236) 1994.

BOSI, Ecléa. O tempo vivo da memória. Ensaios de psicologia social. São Paulo: Ateliê Editorial, 2003.

CAMPOS, Haroldo. http://www.dw-world.de/dw/article/0,2144,951490,00.html consulta outubro 2007.

COURBIN, Alain. L'homme dans le paysage. Paris: Les éditions textuel, 2001.

DE CERTEAU, Michel. A invenção do cotidiano: artes de fazer. Petrópolis: Vozes, 1994.

DURAND, Gilbert. A imaginação simbólica. São Paulo: Cultrix, 1988.

DURAND, Gilbert. As estruturas antropológicas do imaginário. Lisboa: Presença, 1989.

ECKERT, Cornelia e ROCHA, Ana Luiza Carvalho. O tempo e a cidade. Porto Alegre: Editora da UFRGS, 2007.

JEUDY, Henri-Pierre. Memórias do social. Rio de Janeiro: Forense Universitária, 1990.

MALDONADO, Simone. Apresentação In: Política \& Trabalho. Setembro de 1996. 12. Editora Universitaria UFPB, PPGS e UFPB. (5-10) 1996.

MORAES FILHO, E. (Org.). Simmel. São Paulo: Editora Ática, 1983.

PESSANHA, José Américo Motta. Bachelard e Monet: o olho e a mão. In: NOVAES, Adauto (Org.). O olhar. São Paulo, Companhia das Letras. (149-165), 1988.

RICOEUR, Paul. O si-mesmo como um outro. Campinas: Papirus, 1991.

RICOEUR, Paul. Tempo e Narrativa. Tomo I, II, III. Campinas: Papirus, 1993.

RICOEUR, Paul. La mémoire, l'histoire, l'oubli. Paris: Seuil, 2000.

SANSOT, Pierre. Les Formes Sensibles de la vie sociale. Paris: PUF, (11-62) 1986.

SANSOT, Pierre. Variations paysagères. Paris: Klincksieck Esthétique, 1983.

SIMMEL, G. A metrópole e a vida mental. In: VELHO, Otávio G. (org). O fenômeno urbano.. Rio de Janeiro, Zahar, (11-25) 1979.

SIMMEL, Georg. A ponte e a porta e a Filosofia da Paisagem. In: Politica \& Trabalho. Setembro de 1996. 12. Editora Universitaria UFPB, PPGS e UFPB (10-24) 1996.

SIMMEL, Georg. Questões fundamentais da sociologia. . Rio de Janeiro: Jorge Zahar, 2006.

WAIZBORT, Leopoldo. As aventuras de Georg Simmel. São Paulo: Editora 34, 2000.

WATIER, Patrick. Georg Simmel sociologue. Paris : Circé, 2003. 